\title{
Ceftriaxone in the treatment of ordinary and penicillinase-producing strains of Neisseria gonorrhoeae
}

\author{
V S RAJAN, E H SNG, T THIRUMOORTHY, AND C L GOH \\ From the Middle Road Hospital, Singapore, Republic of Singapore
}

SUMMARY Ceftriaxone, a third generation cephalosporin, was used in a single intramuscular dose with oral probenecid to treat 124 men with infections due to non-penicillinase-producing Neisseria gonorrhoeae (non-PPNG) and 64 men with infections due to PPNG. Three different doses of ceftriaxone were used-125 mg, $62.5 \mathrm{mg}$, and $32.5 \mathrm{mg}$. The cure rate for all PPNG infections with the different doses was $100 \%$. The cure rate for the non-PPNG infections with ceftriaxone $125 \mathrm{mg}$ was $100 \%$; those for non-PPNG infections treated with ceftriaxone $62.5 \mathrm{mg}$ and $32 \cdot 5 \mathrm{mg}$ were $96 \cdot 2 \%$ and $97 \cdot 3 \%$ respectively. The 160 strains of non-PPNG and 60 strains of PPNG isolated were all susceptible to ceftriaxone with minimum inhibitory concentrations of $0.008 \mu \mathrm{g} / \mathrm{ml}$. These results are compared with those using kanamycin $2 \mathrm{~g}$. Ceftriaxone is a safe and effective treatment for PPNG and non-PPNG infections.

\section{Introduction}

The first cephalosporin was isolated in 1955 and since then different generations, each showing advantages over the previous one, have been produced. The newer generations show increasing activity, a broader antimicrobial spectrum, and increased stability to penicillinase.

When compared with other cephalosporins of the same class $^{12}$ ceftriaxone, a new third generation cephalosporin, has been found to be highly active against strains of both penicillinase-producing Neisseria gonorrhoeae (PPNG) and non-penicillinaseproducing $N$ gonorrhoeae (non-PPNG). Ceftriaxone is an aminothiazolyl-oxyimino-cephalosporin, which is different from other cephalosporins in the nature of the substitution at position 3 of the nucleus (figure). The presence of an enolate axion group at the triazine moiety of the 3-substituent probably contributes to its long plasma half-life.

The bioavailability of ceftriaxone when dissolved in water or $1 \%$ lignocaine given by the intramuscular route is about $100 \% .^{3}$ Regardless of the dose administered the half-life of the drug in the plasma is $6 \cdot 5-8 \cdot 6$ hours in healthy adults. The plasma half-life of all other cephalosporins is relatively short, ranging from 45 minutes to $21 / 2$ hours.

Address for reprints: Dr V S Rajan, Middle Road Hospital, Singapore 0718, Republic of Singapore

Accepted for publication 10) May 1982

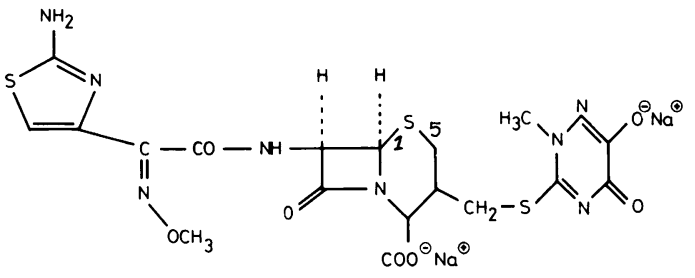

FIGURE Chemical structure of ceftriaxone

In man the drug is not metabolised and about $40 \%$ of the unchanged compound is eliminated in the bile; $60 \%$ of the injected dose is excreted in the urine. ${ }^{3}$

A clinical study was performed to determine the effectiveness of ceftriaxone against PPNG and nonPPNG infections in male patients. Comparisons were made with patients treated with kanamycin, the present drug of choice for the treatment of gonorrhoea in Singapore. Different doses of ceftriaxone were administered and the results recorded.

\section{Patients and methods}

\section{DIAGNOSIS}

Four hundred and eleven male patients with acute gonococcal urethritis were studied. Gonorrhoea was diagnosed when Gram-negative intracellular diplococci were seen on microscopy of a Gram-stained smear and the gonococcus was isolated on modified Thayer-Martin media. Penicillinase production was 
tested in all isolated cases by the disc diffusion method using a penicillin disc (10 IU) and confirmed by a rapid iodometric method. ${ }^{4}$ Isolates of $N$ gonorrhoeae whose growth was not inhibited by a penicillin disc were examined for the production of $\beta$-lactamase by the rapid iodometric method.

\section{TREATMENT}

When Gram-negative intracellular diplococci were seen in urethral smears treatment was given. Only those treated patients whose infections were confirmed by culture were included in the study. Two hundred and six patients were given a single intramuscular dose of $2 \mathrm{~g}$ kanamycin; 205 were given a single intramuscular dose of ceftriaxone $125 \mathrm{mg}$ or $62.5 \mathrm{mg}$ or $32.25 \mathrm{mg}$ with $1 \mathrm{~g}$ probenecid orally. Patients were grouped for study according to the dose of ceftriaxone given.

\section{Group $A$}

Sixty male patients received a single intramuscular injection of ceftriaxone $125 \mathrm{mg}$ and probenecid $1 \mathrm{~g}$ orally.

\section{Group B}

Eighty-seven patients were treated with a single intramuscular injection of ceftriaxone $62.5 \mathrm{mg}$ and probenecid $1 \mathrm{~g}$ orally.

\section{Group C}

Fifty-eight patients were treated with ceftriaxone $32.25 \mathrm{mg}$ intramuscularly and probenecid $1 \mathrm{~g}$ orally.

\section{Kanamycin group}

Two hundred and six men with gonococcal urethritis were treated with kanamycin in a single intramuscular dose of $2 \mathrm{~g}$.

\section{FOLLOW UP AND TEST OF CURE}

All patients in the study were reassessed on days 5 and 14 after treatment. A clinical assessment followed by a urethral smear for Gram staining and culture for $N$ gonorrhoeae was made on each visit. Any unwanted effects of treatment were noted. Treatment failure was considered if any of the Gramstained smears or cultures gave positive results. Patients with reinfections were excluded from the study. Post-gonococcal urethritis was diagnosed on day 14 in symptomatic patients with pus cells $(\geqslant 10$ high-power field) on the Gram-stained smear and a negative culture result for $N$ gonorrhoeae. Chlamydial cultures were not attempted.

\section{ANTIBIOTIC SUSCEPTIBILITY}

Antibiotic susceptibility tests were performed on 160 non-PPNG and 60 PPNG strains isolated. The minimum inhibitory concentrations (MICs) of ceftriaxone were determined by the agar plate dilution method. 5 Twofold concentrations of ceftriaxone from 0.000063 to $0.008 \mu \mathrm{g} / \mathrm{ml}$ were used.

\section{Results}

The details of the treatment response are given in table I. There were no treatment failures in all three groups of patients infected with PPNG when treated either with ceftriaxone with probenecid or with kanamycin. The overall failure rate with kanamycin in the patients infected with non-PPNG strains was $11 \%$.

\section{POSTGONOCOCCAL URETHRITIS}

There was no significant difference in the incidence of postgonococcal urethritis in patients treated with kanamycin or with ceftriaxone. The overall incidence of postgonococcal urethritis in patients treated either

TABLE I Response of patients with gonorrhoea due to PPNG and non-PPNG strains to various doses of ceftriaxone and probenecid compared with kanamycin

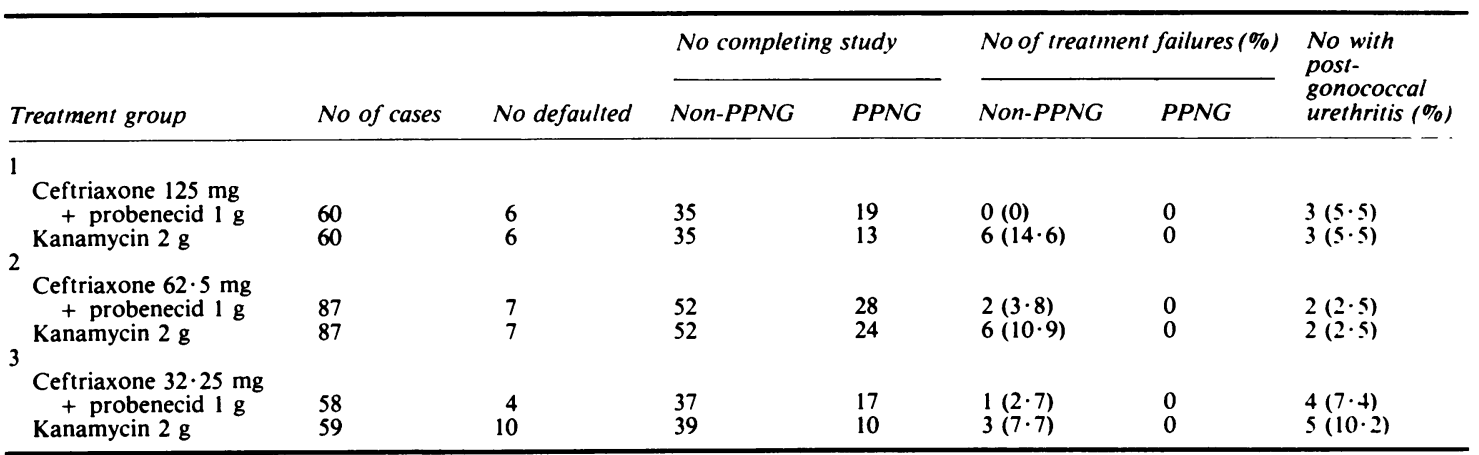

PPNG = penicillinase-producing $N$ gonorrhoeae 
TABLE II Susceptibility of Neisseria gonorrhoeae to ceftriaxone

\begin{tabular}{|c|c|c|c|c|c|c|c|c|c|}
\hline \multirow[b]{2}{*}{ Strains } & \multirow[b]{2}{*}{ No } & \multicolumn{8}{|c|}{ Minimum inhibitory concentration $(\mu \mathrm{g} / \mathrm{ml})$} \\
\hline & & 0.000063 & 0.000125 & 0.00025 & 0.0005 & 0.001 & 0.002 & 0.004 & 0.008 \\
\hline $\begin{array}{l}\text { PPNG } \\
\text { Non-PPNG }\end{array}$ & $\begin{array}{r}60 \\
120\end{array}$ & $\begin{array}{l}1 \\
1\end{array}$ & $\begin{array}{l}1 \\
5\end{array}$ & $\begin{array}{l}6 \\
9\end{array}$ & $\begin{array}{l}12 \\
42\end{array}$ & $\begin{array}{l}23 \\
37\end{array}$ & $\begin{array}{l}12 \\
16\end{array}$ & $\begin{array}{l}4 \\
7\end{array}$ & $\begin{array}{l}1 \\
3\end{array}$ \\
\hline
\end{tabular}

PPNG = penicillinase-producing $N$ gonorrhoeae

with kanamycin or with ceftriaxone was $5.4 \%$ and $4 \cdot 4 \%$ respectively.

\section{SIDE EFFECTS}

No serious side effects or local reactions to the injections were reported. A few patients had a little discomfort after injections of both kanamycin and ceftriaxone.

\section{ANTIBIOTIC SUSCEPTIBILITY}

The results of the antibiotic susceptibility to ceftriaxone are given in table II. All the 120 non-PPNG and 60 PPNG strains were susceptible to $0.008 \mu \mathrm{g} / \mathrm{ml}$ of ceftriaxone. There was no difference in the susceptibility of non-PPNG and PPNG strains. The geometric means of the MICs of the drug for PPNG and non-PPNG strains were $0 \cdot 00018 \mu \mathrm{g} / \mathrm{ml}$.

\section{Discussion}

The effectiveness of the newer cephalosporins (cefuroxime, cefoxitin, cefotaxime) in the treatment of PPNG and non-PPNG infections has been well documented. ${ }^{5-7}$ Ceftriaxone is a third generation cephalosporin. In this study the clinical response to ceftriaxone in acute gonococcal infection was extremely good. The overall cure rate for the infections due to PPNG strains was $100 \%$. With the 125 -mg dose of ceftriaxone the cure rate for the nonPPNG infections was $100 \%$. With doses of $62.5 \mathrm{mg}$ and $32.25 \mathrm{mg}$ ceftriaxone the rates were $96.2 \%$ and $\mathbf{9 7} \cdot \mathbf{3 \%}$ respectively. All these results are acceptable as effective treatment for gonorrhoea.

Although there was a slight difference in the clinical response of the PPNG and non-PPNG strains to ceftriaxone the antibiotic susceptibility in vitro was the same. This differed from the results of our previous study, ${ }^{5}$ in which cefotaxime had a greater inhibitory effect on the PPNG strains. Our experience also differs from that of Thabaut et al, ${ }^{2}$ who suggested that the non-PPNG strains seemed to be more susceptible to ceftriaxone. Nevertheless, our study agrees with others in showing that ceftriaxone has high activity at low levels when compared with all other cephalosporins. ${ }^{12}$

The gonococcus has shown great resistance over the years and needs progressively increasing doses of penicillin to inhibit its growth both in vitro and in vivo. In 1976 totally resistant penicillinase-producing strains were isolated. The Pacific and South-east Asian regions have shown alarmingly high prevalences of PPNG strains. ${ }^{8}$ At the same time Southeast Asian non-PPNG strains have become resistant to several antibiotics and show their robustness by producing greater failure rates to established antibiotics and even newer antibiotics such as cefotaxime and ceftriaxone. ${ }^{9}$ In 1979 in Singapore the success rate with kanamycin $2 \mathrm{~g}$ was $100 \%$ for all gonococcal infections (Rajan, personal communication). In 1981 , in this study, the overall success rate was $91.9 \%$ for the non-PPNG strains. Until now, all strains of gonococci in Singapore have been susceptible to kanamycin at $16 \mu \mathrm{g} / \mathrm{ml}$ (Sng, personal communication). Nevertheless, the non-PPNG strains in Singapore are being carefully watched because of their multiple resistance to several antibiotics.

Thus, ceftriaxone in a single dose is safe and effective in treating both PPNG and non-PPNG infections. In the light of the increasing partial resistance of South-east Asian gonococcal strains to several antibiotics the optimum dose should not be less than $125 \mathrm{mg}$ intramuscularly with $1 \mathrm{~g}$ probenecid orally.

\section{References}

1. Prere MF, Lefervre JC, Lareng MB. Study of the in-vitro activity of new cephalosporins on strains of the Toulouse Region. Chemotherapy 1981;27 suppl 1:15-8.

2. Thabaut A, Durosoir JL, Saliou P. Comparative in-vitro activity of eight cephalosporins on 109 strains of $N$ gonorrhoeae and 60 strains of $N$ meningitidis. Chemotherapy 1981;27 suppl 1:19-24.

3. Stoeckel K. Pharmacokinetics of recephin, a highly active new cephalosporin with an exceptionally long biological half-life. Chemotherapy $1981 ; 27$ suppl 1:42-6.

4. Sng EH, Yeo KL, Rajan VS, Lim AL. Comparison of methods for the detection of penicillinase-producing Neisseria gonorrhoeae. Br J Vener Dis 1980; 56:311-3

5. Rajan VS, Sng EH, Pang R, Tan NJ, Thirumoorthy T, Yeo KL. HR-756-a new cephalosporin in the treatment of gonorrhoea caused by ordinary and penicillinase-producing strains of $N$ gonorrhoeae. Br J Vener Dis 1980; 56:255-8.

6. Price JD, Fluker JL. The efficacy of cefuroxime for the treatment of acute gonorrhoea in men. Br J Vener Dis 1978:54: 165-9.

7. Arya OP, Rees E, Percival A, Alergant CD, Annels EH, Turner GC. Epidemiology and treatment of gonorrhoea caused by penicillinase-producing strains in Liverpool. Br J Vener Dis 1978;54:28-35.

8. Rajan VS, Thirumoorthy T, Tan NJ. Epidemiology of penicillinase-producing $N$ gonorrhoeae in Singapore. $\mathrm{Br}$ Vener Dis 1981;57:158-61.

9. Rajan VS, Tan NJ, Tan T, Khoo R, Sng EH, Pang CP. Treatment of gonorrhoea: the Singapore experience. Asian $j$ Infect Dis 1977;1:71-4. 